\title{
A New Era in Infectious Disease Testing
}

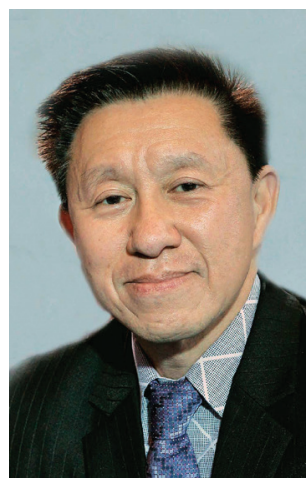

Scarcely a year ago, we heard the rumblings of a looming pandemic. What followed was a journey of selfdiscovery for the Philippine Society of Pathologists and its members. Early on, we watched helplessly while the pandemic raged on in our country, handicapped by the lack of laboratory resources to test the increasing number of cases. Only the Research Institute for Tropical Medicine (RITM) was equipped and enabled to test for SARS-CoV-2 at that point in time. Most molecular testing was done in private hospitals where the emphasis was on oncology.

The Department of Health launched a program to set up molecular laboratories across the country and pathologists joined in the scramble to capacitate their own laboratories to fight the pandemic. Meanwhile, testing was still very limited and patients were dying without being diagnosed as results were delayed up to two weeks.

The PSP set up a Viber group as a venue for its members to discuss the ongoing events and assist each other with information. This was crucial as the lockdown prevented in person meetings. Upon inquiring with former PSP president Dr. Bernadette Espiritu, the PSP had issued a statement on rapid antibody testing but had not gotten to the point of addressing the society's position on the best response to the pandemic. I suggested we craft a position paper on what we can offer in terms of laboratory testing. What followed was a series of Zoom meetings where we discussed and debated the contents of the PSP statement.

In late May 2020, the PSP released its position paper and almost immediately, the DOH, through USec. Ma. Rosario Vergeire, invited us to present our position paper to the newly formed COVID Lab Experts Panel (CLEP), which at that time did not have a single pathologist in its membership, which was composed mostly of molecular scientists from the academe.

Our position paper was well received and we were encouraged to come up with a proof-of-concept paper on pooled testing which we had advocated as a means of testing on a wider scale than can be done with individual RT-PCR testing. As a result of that meeting, where we pointed out the obvious lack of pathologist representation in the CLEP, Dr. Socorro Yanez and myself were invited to join, a good sign that pathologists are now being taken seriously in the pandemic response.

Again, we had a series of night-long meetings where we crafted the research proposal, which was presented to the CLEP for their approval. It was endorsed to the $\mathrm{DOH}$ and subsequently, we were given the go-ahead signal.

During this period, we had the good fortune to be contacted by the Philippine Chamber for Entrepreneurship Foundation Inc., locally better known as GoNegosyo through its RT-PCR Chief Implementor, Dr. Janette Loreto-Garin (Congresswoman of Iloilo). A partnership was born out of the mutual desire to help the ailing Philippine economy suffering its worst contraction since the Marcos years. GoNegosyo graciously agreed to fund the research and we proceeded with alacrity to pursue the research. We are eternally grateful to Mr. Jose Concepcion III, founder of GoNegosyo, Josephine Romero, Project Leader for Project Ark / GoNegosyo COVID-19 Response Initiative, Dr. Criselda Abesamis, PCE Project Consultant and Coordinator for Pooled PCR Testing (a fellow pathologist) and Dr. Garin for forging a lasting relationship with our society.

As a multi-institutional study, it was necessary to clear the Institutional Review-Ethics Committee of each of these institutions, RITM, Philippine Children's Medical Center (PCMC) and University of Perpetual HelpDALTA Medical Center. It took more than a month to secure clearance but in late July we had done Experiment 1 at the RITM, which laid the basis for Experiment 2, done in early August.

When the initial write up of the research was done, the authors met again, this time in person, to finalize the concept paper and provide the necessary framework for pooled testing implementation, including guidelines, quality assurance schemes and training modules for both specimen collection as well as pooled testing and interpretation of results.

By September, we had finished the research and it was presented to the combined panels of CLEP, Technical Advisory Group (TAG) and Health Technology Assessment Council (HTAC), where it was well received. 
More hurdles laid ahead. We had to present the pooled testing concept to the Inter- Agency Task Force (IATF) for COVID Response, initially as a concept and later as a finished research complete with the aforementioned accompanying documents. The response was encouraging.

Still, approval was not yet forthcoming. We then initiated pilot project implementation of pooled testing in several LGUs which further resulted in more refinements and process improvements in the pooled testing concept.

Once more, in October, we presented our pilot project results to the CLEP-TAG-HTAC joint meeting. There was consensus that pooled testing will be useful and it was again endorsed to the $\mathrm{DOH}$ for final decision. As the HTAC was the last arbiter before approval, it fell on its members to endorse the program to the $\mathrm{DOH}$.

Finally, in late December, our pooled testing program was finally approved with the issuance of the Interim Guidelines on the Conduct of COVID-19 Pooled Testing (dated November 23, 2020 but released December 29, 2020).

It was a long journey but we have proven that we, as pathologists, the real clinical laboratory experts, can contribute to the efforts to mitigate the effects of the pandemic and in the process, make ourselves heard and recognized on the national scene.

Our contribution marks a significant milestone in our Society's history. It is not only a game changer in itself but a first worldwide. Though pooled testing has been done earlier in different countries, no other country has made an effort to systematize and conduct pooled testing on a comprehensive basis such as ours. This complete package of pooled testing will stand as a testament to the hard work, dedication and persistence of members of the PSP who believed they can make a difference.

Our pooled testing process will not only make a difference in our current situation, but I believe it is a lasting contribution to the Philippines, if not the whole world, that will make itself useful in response to future pandemics, and we all know in our hearts and minds, the COVID-19 pandemic will not be the last.

To my fellow pathologists, I salute and thank you for your courage, determination and fortitude in undertaking this journey and in the process, prove to ourselves we have the capacity to lead and to effect change, eventually in recognition of the PSP as leader in the medical field.
The COVID-19 pandemic has indeed changed the entire landscape of clinical laboratory testing. We have gone from being way behind in molecular testing to being quickly capacitated in response to this existential threat to mankind. It has been both a bane and a boon to pathologists. A crisis, as the Chinese proverb says, is both a danger and an opportunity. We grabbed the crisis by the horns ad successfully wrestled it by coming up with our innovation in pooled testing.

It is therefore with great pleasure that we publish this portfolio of work in the Philippine Journal of Pathology as a tribute to the Philippine Society of Pathologists Inc. and the Philippine Chamber for Entrepreneurship Foundation Inc.

May this serve as an inspiration for our Filipino pathologists to engage and be more active in world class research that can be published in our very own Philippine Journal of Pathology.

Mabuhay ang Philippine Society of Pathologists Inc.!

\section{Raymundo W. Lo, MD, FPSP}

Principal Investigator

\section{Postscript:}

Special thanks to the following who did the legwork with us during the sample collection for Experiment 2 , risking their safety by coming face-to-face with our research subjects: Drs. Farrah Fontilla-Santiago, MD, FPSP, Melani Hernandez-Sionzon, MD, FPSP, Socorro Yanez, MD, FPSP, Bernadette Espiritu, MD, FPSP, Agnes Barrientos, MD, FPSP, Mr. Eidelbert Santiago, RN and the PCMC COVID Testing Laboratory Analysts and swabbers.

Also special mention of Amado Tandoc III, MD, FPSP, our indefatiguable Chief of the Laboratory Research Division, RITM who handled Experiment 1 and crafted the Verification Procedure, and Mark Ang, MD, FPSP, who did the statistical analysis for this research.

https://doi.org/10.21141/PJP.2020.15 